\title{
Elastofibroma dorsi: Surgical indications and complications of a rare soft tissue tumor
}

\author{
SATOSHI NAGANO ${ }^{1}$, MASAHIRO YOKOUCHI ${ }^{1}$, TAKASHI SETOYAMA ${ }^{1}$, HIROMI SASAKI $^{1}$, \\ HIROFUMI SHIMADA ${ }^{1}$, ICHIRO KAWAMURA ${ }^{1}$, YASUHIRO ISHIDOU ${ }^{2}$, \\ TAKAO SETOGUCHI $^{3}$ and SETSURO KOMIYA ${ }^{1}$
}

\begin{abstract}
Departments of ${ }^{1}$ Orthopaedic Surgery and ${ }^{2}$ Medical Joint Materials; ${ }^{3}$ The Near-Future Locomotor Organ Medicine Creation Course (Kusunoki Kai), Graduate School of Medical and Dental Sciences, Kagoshima University, Kagoshima, Kagoshima 890-8520, Japan
\end{abstract}

Received November 21, 2013; Accepted January 31, 2014

DOI: $10.3892 / \mathrm{mco} .2014 .257$

\begin{abstract}
Elastofibroma dorsi (ED) is a tumor that develops in the space between the lower angle of the scapula and the posterior thoracic wall. Due to the rarity of this type of tumor, the number of reported consecutive series is limited. Surgical excision, usually recommended for symptomatic cases to confirm diagnosis and relieve symptoms, has been associated with a high complication rate. To analyze the clinical characteristics and outcomes of surgical treatment, we retrospectively reviewed 20 consecutive cases of surgically resected ED. Of the 20 patients, 14 (70\%) exhibited preoperative symptoms associated with the tumor. The mean diameter of the resected tumors averaged $72 \mathrm{~mm}$ (range, $45-110 \mathrm{~mm}$ ). The surgical outcomes were satisfactory, except for the development of hematoma or seroma in 9 cases (43\%), 8 of which achieved a complete resolution with conservative treatment. Age, hypertension, the presence of preoperative tumor-related symptoms and intraoperative bleeding were not found to be significantly associated with the incidence of hematoma. However, tumor diameter and the duration of postoperative drainage were significantly associated with occurrence of hematoma $(\mathrm{P}=0.02$ and $\mathrm{P}=0.01$, respectively). Surgical resection should only be recommended for symptomatic patients, due to the high incidence of postoperative complications. To prevent the development of postoperative hematoma or seroma, careful observation of the wound, with suction drainage for $>7$ days and additional surgical procedures to facilitate adhesion of the wound margins, are recommended.
\end{abstract}

Correspondence to: Dr Satoshi Nagano, Department of Orthopaedic Surgery, Graduate School of Medical and Dental Sciences, Kagoshima University, 8-35-1 Sakuragaoka, Kagoshima, Kagoshima 890-8520, Japan

E-mail: naga@m2.kufm.kagoshima-u.ac.jp

Key words: elastofibroma dorsi, soft tissue tumor, hematoma, surgery

\section{Introduction}

Elastofibroma dorsi (ED) is a rare tumor that develops in the space between the lower angle of the scapula and the posterior thoracic wall. Microscopically, the tumor consists of proliferated fibroblasts and accumulated abnormal elastic fibers. The pathogenesis of this tumor has not been fully elucidated, although mechanical friction between the chest wall and the inferior tip of the scapula may be involved in the development of ED. Giebel et al (1) hypothesized, based on the discovery of pre-elastofibroma-like changes in $81 \%$ of their autopsy series, that ED may be part of the aging process. The high incidence of bilateral lesions $(33-100 \%)(2,3)$ also indicates the reactive nature of this type of tumor. In a large study of $170 \mathrm{ED}$ cases, Nagamine et al (2) reported that $32 \%$ of the cases occurred within a single family, suggesting a familial predisposition for ED. Although the etiology of ED remains unclear, mechanical and genetic factors have been implicated in its development.

As ED is a benign, slow-growing tumor, it may be observed without treatment following diagnosis based on the clinical and imaging characteristics. Symptomatic patients typically present with snapping of the scapula, with or without pain, on abduction and adduction of the shoulder. Surgical excision is usually indicated for snapping scapula or tumor-related discomfort. Several authors reported that marginal resection of ED significantly relieves the symptoms (4-6). However, a high incidence of postoperative complications, such as development of seroma or hematoma, has been reported (5,7). Previous studies recommend 3 weeks of immobilization of the affected upper extremity (6) or postoperative wound drainage and a compression bandage to avoid these complications (8). Due to the rarity of this tumor, the optimal operative approach and postoperative treatment have not yet been determined. In this study, we retrospectively reviewed 20 cases of surgically treated ED to determine the association between postoperative complications and preoperative patient characteristics or postoperative treatment.

\section{Materials and methods}

Patients. A total of 20 consecutive cases of ED [ 8 men and 12 women; mean age, 63 years (range, $41-76$ years)] who were 
surgically treated at our institution between 2000 and 2012 were retrospectively analyzed. The preoperative presentation of any symptoms or disability and postoperative improvement were reviewed.

Pre- and postoperative evaluation. All the cases were evaluated with magnetic resonance imaging (MRI) prior to surgery. In 2 cases, biopsy had been performed by the primary physician prior to referring the case to our institution. All the patients underwent marginal resection and the diagnosis was confirmed by a pathologist. To investigate factors that may affect postoperative complications, the presence of hypertension, tumor size, intraoperative bleeding and duration of postoperative wound drainage were evaluated.

Prevalence. To evaluate the prevalence of ED in Japan, the Soft Tissue Tumor Registry (Musculoskeletal Tumor Committee, Japanese Orthopaedic Association), available since 2008 for benign and malignant soft tissue tumors, was reviewed.

The present study was planned and conducted in accordance with the ethical standards of the responsible committee on human experimentation and conformed to the principles of the Declaration of Helsinki.

\section{Results}

Clinical presentation. Fourteen patients (70\%) presented with symptoms associated with the tumor, including discomfort ( 3 cases), pain around the scapula (6 cases) and snapping of the scapula with shoulder motion (4 cases). The mass was incidentally discovered by the patient or by another person, such as a family member, in 6 asymptomatic patients. Although mechanical stress is suspected to be a cause of this disease, the occupations of the patients varied and included physical labor ( 7 cases), office work ( 7 cases) and being unemployed or working from home (6 cases) (Table I). ED was preoperatively diagnosed based on location and imaging findings, although biopsy was performed in the primary hospital in 2 cases. Preoperative MRI revealed an unencapsulated and lenticular-shaped mass of low intensity in T1-weighted images and iso- or low-intensity in T2-weighted images, reflecting the fibrous tissue content of the mass (Fig. 1), which is in contrast to the characteristic high-intensity strands produced by fatty tissue on T1-weighted images and intermediate-intensity strands on $\mathrm{T} 2$-weighted images.

Treatment. Based on the preoperative diagnosis of ED, all the patients underwent marginal resection of the tumor. The standard operative approach starts with a skin incision just superior to the mass, followed by splitting of the latissimus dorsi muscle to reveal the edematous serratus anterior muscle. By splitting the serratus anterior muscle, the white and ill-defined tumor mass is exposed. In the majority of the cases, the tumor was firmly adherent to the serratus anterior muscle and thoracic wall, requiring sharp dissection using scissors or electrocautery.

Macro- and microscopic characteristics. Macroscopically, the resected tumors were whitish, firm and an average of $72 \mathrm{~mm}$ (range, 45-110 mm) in diameter. The cut surface was white and yellow, reflecting mixed fibrous and fatty tissues.
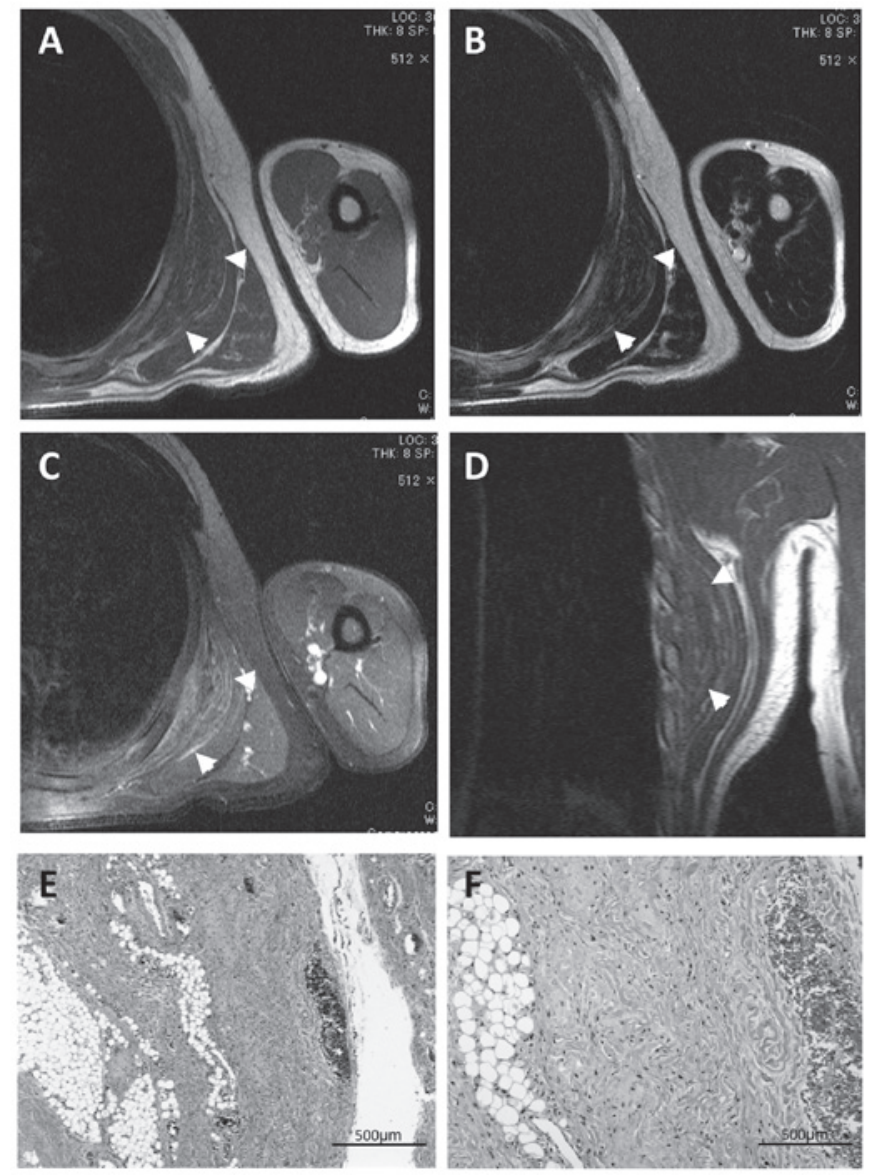

Figure 1. Typical magnetic resonance imaging (MRI) and pathological characteristics of elastofibroma dorsi. (A and B) A 64-year-old male patient presented with a mass in the right subscapular area. MRI revealed a lenticular-shaped mass appearing as low- to iso-intense on T1- and T2-weighted images, with high-intensity strands reflecting the fat tissue inside the tumor. (C) Gadolinium injection resulted in scattered enhancement within the tumor. (D) The mass is located between the serratus anterior muscle and the posterior thoracic wall on coronal view. (E and F) Hematoxylin and eosin staining revealed elastic and collagen fibers coexisting with mature adipose tissue. Arrowheads, tumor borders.

On pathological examination, elastic and collagen fibers coexisted with mature adipose tissue (Fig. 1E and F).

Complications. Postoperative hematoma occurred in 9 cases (43\%) and resolved with conservative treatment in 8 cases (Table I). One case with a massive postoperative hematoma was treated with surgical evacuation, which resulted in successful healing of the wound. Due to the high incidence of postoperative hematoma, we analyzed the factors that may affect the development of hematoma following ED resection. Age, hypertension, the presence of preoperative tumor-related symptoms and intraoperative bleeding were not found to be significantly different between patients with $(n=9)$ or without $(n=11)$ postoperative hematoma (Table II), although tumor diameter was significantly larger in the hematoma group $(\mathrm{P}=0.02)$ and the duration of postoperative drainage was significantly longer in the non-hematoma group $(\mathrm{P}=0.01$, Table II).

Prevalence. The analysis of the Soft Tissue Tumor Registry database revealed 130 cases of ED among a total of 12,557 soft tissue tumor cases (1.0\%). The distribution analysis of 
Table I. Summary of patients with elastofibroma dorsi.

\begin{tabular}{|c|c|c|c|c|c|c|c|c|c|}
\hline Patient & $\begin{array}{c}\text { Gender/ } \\
\text { Age } \\
\text { (years) }\end{array}$ & Location & Symptom & Occupation & Hypertension & $\begin{array}{c}\text { Intraoperative } \\
\text { bleeding }(\mathrm{g})\end{array}$ & Hematoma & $\begin{array}{l}\text { Wound } \\
\text { drainage } \\
\text { (days) }\end{array}$ & $\begin{array}{c}\text { Tumor } \\
\text { diameter } \\
(\mathrm{mm})\end{array}$ \\
\hline 1 & $\mathrm{M} / 42$ & $\mathrm{R}^{\mathrm{a}}$ & Pain & Office worker & & 50 & + & 2 & 110 \\
\hline 2 & $\mathrm{M} / 41$ & $\mathrm{~L}^{\mathrm{a}}$ & Snapping & Office worker & & 130 & + & 2 & 95 \\
\hline 3 & $\mathrm{~F} / 72$ & $\mathrm{~L}$ & & Liquor-shop employee & + & 10 & + & 4 & 90 \\
\hline 4 & $\mathrm{~F} / 70$ & $\mathrm{R}$ & & Farmer & & 15 & + & 4 & 110 \\
\hline 5 & $\mathrm{M} / 63$ & $\mathrm{R}$ & & Office worker & & 100 & + & 3 & 90 \\
\hline 6 & $\mathrm{M} / 45$ & $\mathrm{R}$ & & Office worker & & 80 & & 7 & 55 \\
\hline 7 & $\mathrm{~F} / 73$ & $\mathrm{~L}^{\mathrm{a}}$ & Snapping & & + & 30 & & 3 & 45 \\
\hline 8 & $\mathrm{~F} / 76$ & $\mathrm{~L}$ & Discomfort & & + & 35 & & 4 & 50 \\
\hline 9 & $\mathrm{~F} / 74$ & $\mathrm{~L}$ & Pain & & & 20 & + & 4 & 55 \\
\hline 10 & $\mathrm{~F} / 50$ & $\mathrm{~B}$ & Snapping & Cook & & 40 & + & 7 & 70 \\
\hline 11 & $\mathrm{~F} / 49$ & $\mathrm{~L}^{\mathrm{a}}$ & Discomfort & & & 10 & & 9 & 48 \\
\hline 12 & $\mathrm{~F} / 73$ & $\mathrm{R}^{\mathrm{a}}$ & Discomfort & & + & 10 & + & 7 & 45 \\
\hline 13 & $\mathrm{~F} / 49$ & $\mathrm{R}$ & & Care manager & & 105 & & 5 & 53 \\
\hline 14 & $\mathrm{M} / 71$ & $\mathrm{~L}$ & Discomfort & Liquor-shop employee & + & 0 & & 7 & 80 \\
\hline 15 & $\mathrm{~F} / 85$ & $\mathrm{~L}$ & Pain & Farmer & + & 5 & & 7 & 70 \\
\hline 16 & $\mathrm{~F} / 58$ & $\mathrm{R}$ & Pain & Nurse & & 15 & & 6 & 70 \\
\hline 17 & $\mathrm{M} / 64$ & $\mathrm{~L}$ & Pain & Office worker & & 125 & & 7 & 90 \\
\hline 18 & $\mathrm{M} / 64$ & $\mathrm{R}^{\mathrm{a}}$ & & Office worker & + & 90 & + & 4 & 80 \\
\hline 19 & $\mathrm{~F} / 79$ & $\mathrm{~L}$ & Pain & & + & 5 & & 7 & 60 \\
\hline 20 & $\mathrm{M} / 58$ & $\mathrm{R}$ & Snapping & Police officer & & 0 & & 7 & 63 \\
\hline
\end{tabular}

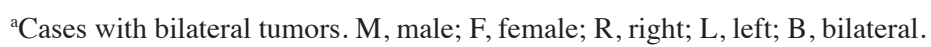

these130 cases revealed no geographic preference regarding the incidence of ED in Japan. In our department, the incidence of ED was estimated to be $2.7 \%$ of the 735 cases of surgically treated soft tissue tumors between 2000 and 2012.

\section{Discussion}

Although ED is traditionally considered to be a rare tumor $(4,9)$, it is a well-recognized entity due to the case reports published by several authors (3-6,9). The incidence of ED in the general population has not been determined; however, Brandser et al (10) reported in their computed tomography (CT) study that ED was found in $2 \%$ of asymptomatic adults aged $>60$ years. The results of that study were based on asymptomatic cases; therefore, the actual prevalence of a symptomatic or palpable ED mass is estimated to be $<2 \%$. A review of the orthopaedic oncology database of the Royal Orthopaedic Hospital in Birmingham, UK, revealed 15 cases of ED out of 17,500 cases $(0.086 \%)$ in $>20$ years $(11)$. In that series from UK, 11 patients underwent tumor resection, whereas 1 patient underwent needle biopsy only. We found the incidence of ED in the Japanese Soft Tissue Tumor Registry to be $1.0 \%$, which is significantly higher compared to the incidence in the UK. The incidence of ED was $2.7 \%$ in our department, which is more consistent with the Japanese registry compared to the UK report (11). This discrepancy may be partly due to the difference in recognition of this entity between UK and Japan; however, genetic factors may also play a role in its geographic distribution. Hisaoka and Hashimoto (12), analyzed 14 cases from Fukuoka, Japan, and demonstrated that spindle or stellate
Table II. Risk factors for postoperative bleeding.

\begin{tabular}{|c|c|c|c|}
\hline Factors & $\begin{array}{l}\text { No hematoma } \\
\qquad(\mathrm{n}=11)\end{array}$ & $\begin{array}{l}\text { Hematoma } \\
\qquad(\mathrm{n}=9)\end{array}$ & $\mathrm{P}$-value \\
\hline Age, years $($ mean $\pm S D)$ & $64.3 \pm 13.5$ & $61 \pm 13.3$ & 0.60 \\
\hline Hypertension (\%) & 52.6 & 47.3 & 0.46 \\
\hline $\begin{array}{l}\text { Preoperative symptom } \\
\text { related to tumor }(\%)\end{array}$ & 47.6 & 52.3 & 0.53 \\
\hline Tumor diameter (mm) & $62.1 \pm 14.1$ & $82.8 \pm 22.7$ & $0.02^{\mathrm{a}}$ \\
\hline $\begin{array}{l}\text { Intraoperative } \\
\text { bleeding }(\mathrm{g})\end{array}$ & $37.3 \pm 45.0$ & $51.7 \pm 44.6$ & 0.48 \\
\hline $\begin{array}{l}\text { Duration of postoperative } \\
\text { drainage (days) }\end{array}$ & $6.27 \pm 1.7$ & $4.1 \pm 1.8$ & $0.01^{\mathrm{a}}$ \\
\hline
\end{tabular}

${ }^{\text {a }}<0.05$ by Student's $\mathrm{t}$-test or Chi-square test was considered to be statistically significant.

cells were positive for CD34. CD34-positive mesenchymal cells are considered to have the potential to differentiate into different lineages, such as endothelial, myoid and adipocytic cells. Congenital or acquired activation of certain factors, including CD34, and long-term mechanical stimulation may cooperatively contribute to the development of symptomatic or palpable ED. Positron-emission tomography (PET) scanning recently became a common screening technique for malignancies. Blumenkrantz et al (13) reported that, among 1,751 patients undergoing PET-CT with ${ }^{18} \mathrm{~F}$-fluorodeoxyglucose (FDG), 29 (1.66\%) were diagnosed with ED. As the ${ }^{18} \mathrm{~F}$-FDG PET scan has becomes more popular for cancer 
screening, more asymptomatic cases of ED may be identified by radiologists. To avoid unnecessary further examination or biopsy, radiologists and physicians should be aware of the characteristic findings of ED $(14,15)$.

Several authors recommend resection for symptomatic cases only $(5,7,11,15)$. In the past, we recommended resection for symptomatic and asymptomatic patients with tumors suspicious for $\mathrm{ED}$, in order to pathologically confirm the diagnosis. However, as the diagnosis of ED is now easily made based on its clinical and imaging characteristics, we only perform tumor resection in symptomatic patients or in those who desire resection of the tumor. Although no case in our study incurred permanent disability associated with postoperative hematoma, the high incidence of hematoma discourages surgical treatment of ED in asymptomatic cases. Other authors reported the incidence of postoperative hematoma or seroma to be $38.9-87.5 \%(4,5,7)$, which is considered to be a high incidence of postoperative complication. As the occurrence of hematoma leads to additional treatment (puncture, immobilization, or surgical evacuation) and longer hospital stay, we generally recommend a week of immobilization of the upper extremity on the affected side and longer suction drainage ( $\sim 1$ week) for ED. The results of the present study demonstrated tumor size and duration of wound drainage to be associated with the incidence of postoperative hematoma. Surgeons should carefully observe the wound postoperatively and apply negative pressure through the drainage tube to facilitate wound healing, particularly in cases of large $(>80-\mathrm{mm})$ tumors.

In a different type of procedure, postoperative seroma was shown to be a significant complication in the donor site of a latissimus dorsi muscle flap (16). Although the dead space is larger in the case of a latissimus dorsi flap compared to that following ED resection, plastic surgeons have described several methods to prevent postoperative seroma. The combination of quilting sutures and fibrin sealant was recently shown to reduce the incidence of postoperative seroma at the donor site $(17,18)$; this may also be applied to surgery for ED.

In conclusion, ED is a rare subscapular lesion affecting mainly the elderly and it is easily diagnosed by its characteristic location and imaging findings. Due to the high incidence of postoperative complications, surgery should be recommended only for symptomatic patients. To prevent the development of postoperative hematoma or seroma, careful observation of the wound with suction drainage and additional surgical procedures to facilitate adhesion of the wound space are recommended.

\section{References}

1. Giebel GD, Bierhoff E and Vogel J: Elastofibroma and preelastofibroma - a biopsy and autopsy study. Eur J Surg Oncol 22: 93-96, 1996.

2. Nagamine N, Nohara Y and Ito E: Elastofibroma in Okinawa. A clinicopathologic study of 170 cases. Cancer 50: 1794-1805, 1982.

3. Naylor MF, Nascimento AG, Sherrick AD and McLeod RA: Elastofibroma dorsi: radiologic findings in 12 patients. AJR Am J Roentgenol 167: 683-687, 1996.

4. Parratt MT, Donaldson JR, Flanagan AM, et al: Elastofibroma dorsi: management, outcome and review of the literature. J Bone Joint Surg Br 92: 262-266, 2010.

5. Muramatsu K, Ihara K, Hashimoto T, Seto S and Taguchi T: Elastofibroma dorsi: diagnosis and treatment. J Shoulder Elbow Surg 16: 591-595, 2007.

6. Muratori F, Esposito M, Rosa F, et al: Elastofibroma dorsi: 8 case reports and a literature review. J Orthop Traumatol 9: 33-37, 2008.

7. Daigeler A, Vogt PM, Busch K, et al: Elastofibroma dorsi - differential diagnosis in chest wall tumours. World J Surg Oncol 5: 15, 2007.

8. Nishio J, Isayama T, Iwasaki H and Naito M: Elastofibroma dorsi: diagnostic and therapeutic algorithm. J Shoulder Elbow Surg 21: 77-81, 2011.

9. Mortman KD, Hochheiser GM, Giblin EM, Manon-Matos Y and Frankel KM: Elastofibroma dorsi: clinicopathologic review of 6 cases. Ann Thorac Surg 83: 1894-1897, 2007.

10. Brandser EA, Goree JC and El-Khoury GY: Elastofibroma dorsi: prevalence in an elderly patient population as revealed by CT. AJR Am J Roentgenol 171: 977-980, 1998.

11. Chandrasekar CR, Grimer RJ, Carter SR, et al: Elastofibroma dorsi: an uncommon benign pseudotumour. Sarcoma 2008: $756565,2008$.

12. Hisaoka $\mathrm{M}$ and Hashimoto $\mathrm{H}$ : Elastofibroma: clonal fibrous proliferation with predominant CD34-positive cells. Virchows Arch 448: 195-199, 2006.

13. Blumenkrantz Y, Bruno GL, Gonzalez CJ, Namias M, Osorio AR and Parma P: Characterization of elastofibroma dorsi with ${ }^{18} \mathrm{FDG}$ PET/CT: a retrospective study. Rev Esp Med Nucl 30: 342-345, 2011 (In English, Spanish).

14. Faccioli N, Foti G, Comai A, Cugini C, Guarise A and Mucelli RP: MR imaging findings of elastofibroma dorsi in correlation with pathological features: our experience. Radiol Med 114: 1283-1291, 2009.

15. Go PH, Meadows MC, Deleon EM and Chamberlain RS: Elastofibroma dorsi: a soft tissue masquerade. Int J Shoulder Surg 4: 97-101, 2010.

16. Sajid MS, Betal D, Akhter N, Rapisarda IF and Bonomi R: Prevention of postoperative seroma-related morbidity by quilting of latissimus dorsi flap donor site: a systematic review. Clin Breast Cancer 11: 357-363, 2011.

17. Bailey SH, Oni G, Guevara R, Wong C and Saint-Cyr M: Latissimus dorsi donor-site morbidity: the combination of quilting and fibrin sealant reduce length of drain placement and seroma rate. Ann Plast Surg 68: 555-558, 2012.

18. Shin IS, Lee DW and Lew DH: Efficacy of quilting sutures and fibrin sealant together for prevention of seroma in extended latissimus dorsi flap donor sites. Arch Plast Surg 39: 509-513, 2012. 